Original Article

\title{
CHARACTERISTICS AND OUTCOME OF PAEDIATRIC LONG BONE FRACTURES MANAGED IN A UNIVERSITY TEACHING HOSPITAL
}

Elachi I.C*, Yongu W.T, Kortor J.N, Mue D.D, Abah R.O. ${ }^{I}$

Departments of Surgery and Paediatrics ${ }^{l}$, College of Health Sciences Benue State University Teaching Hospital, Makurdi.

*Corresponding Author: Itodo Cornelius Elachi Department of Surgery, College of Health Sciences, Benue State University Teaching Hospital, Makurdi, elachitodo@gmail.com

Received date: April $25^{\text {th }} 2018$, Accepted date: June $7^{\text {th }}$ 2018. Published date: June $30^{\text {th }} 2018$.

\section{Abstract}

Fractures constitute a significant component of paediatric trauma. Paediatric fractures account for significant morbidity. This study was set to elucidate the characteristics and outcome of paediatric fractures in a university teaching hospital. Case notes were reviewed for socio-demographic and clinical variables. Statistical analysis was carried out using the software Statistical Package for Social Sciences for Windows, Version 21.0. The correlation between development of complications and prior treatment by traditional bone setters was determined using chisquared tests. Fifty four long bone fractures were studied in 52 children. Their ages ranged from 1 day to 16 years with a mean of $8.85 \pm 3.86$ years. There were 29 males $(55.8 \%)$ and 23 females (44.2\%). The aetiology of childhood fractures included road traffic crashes $(n=30,57.7 \%)$, falls $(n=10,19.3 \%)$, sports injuries $(n=8,15.4)$. The long bones fractured were tibia $(n=19,35.2 \%)$, femur $(n=14,25.9 \%)$, distal radius $(n=14,25.9 \%)$ and supracondylar part of the humerus $(n=7,13.0 \%)$. Non-operative treatment modalities were the most frequent means employed in treating children with fractures in this study. Limb gangrene following prior treatment by traditional bone setters was the most common complication. There was a statistically significant correlation between development of complications and prior traditional bone setters treatment $(\mathrm{p}<0.001)$. Paediatric fractures were more common in boys, caused mostly by road traffic crashes. Most were patients discharged without deformities. Public enlightenment on trauma prevention, enforcement of school bus transport system and reducing street hawking by expanding school feeding programmes may help reduce incidence of paediatric fractures.

Keywords: Children, Complications, Fractures, Road Traffic Injuries.

\section{Introduction}

Trauma is an important cause of childhood morbidity and mortality globally. ${ }^{1,2}$ About 5 million children die from trauma each year. ${ }^{3}$ Fractures are a common occurrence in childhood constituting about 10 to $25 \%$ of all paediatric injuries. ${ }^{4}$ The lifetime risk of sustaining a fracture in childhood is approximately 42 $64 \%$ in males and $27-40 \%$ in females, with remarkable variation in the estimates worldwide. ${ }^{5}$

Childhood fractures commonly result from falls and traffic injuries. While falls in and around the home account for most paediatric fractures in western countries, fractures from road traffic crashes predominate in Nigeria. ${ }^{6-9}$ In many low-income and middle-income countries, children are prone to road traffic crashes (RTC) because the road is a shared space for playing, working, walking, cycling and driving. ${ }^{10}$ Most children involved in traffic-related injuries are usually pedestrians and passengers; child pedestrian injury rates have been found to be highest in Africa and Asia because many children walk to school. $^{11}$

Although operative fixation is absolutely indicated for the treatment of some paediatric fractures, most are amenable to conservative modes of treatment. ${ }^{12}$ The greater sub-periosteal hematoma that occurs in childhood fractures and the stronger periosteum contribute to rapid formation of callus and quicker healing than fractures in adults. ${ }^{13}$ Despite the fact 
these fractures heal easily, meddlesome interventions by traditional bone setters in low-income countries may result in increased morbidity and occasional mortality. ${ }^{14}$

The World Health Organization describes fractures as the most common category of unintentional injuries suffered by children below 15 years and requiring hospital admission in developing countries. ${ }^{15}$ The discomfort and lost school days add to the morbidity of these fractures.

There is paucity of data on childhood fractures in Nigeria and the study setting in particular. Such information is necessary for assessing the impact of trauma on child health and for setting priorities to improve paediatric injury care. The aim of this study was to outline the characteristics and outcome of childhood fractures in a university teaching hospital in a bid to developing preventive strategies for Public Health policy formulation.

\section{Materials and methods}

This was a descriptive retrospective study of children aged 0-16 years with long bone fractures seen from June 2012 to May 2017 at Benue State University Teaching Hospital, Makurdi, Nigeria (BSUTH). The hospital, located along the shores of the River Benue, is a tertiary care center and teaching hospital affiliated to the Benue State University. It is a 350-bed hospital and serves as the major treatment center for trauma patients in Makurdi. Children aged 0-16 years with clinical and radiological evidence of one or more long bone fractures were included in the study. Patients with incomplete medical records were excluded from the study.

Patients' case notes were reviewed for demographic and clinical variables including age, gender, anatomic site of injury, nature of fracture (open or close), mechanism of injury, associated injuries, prior treatment by traditional bone setters (TBS ), treatment given, complications and outcome. Children were classified based on age into neonates (0-28 days), infants (1 to <12 months), toddlers (1-3 years), preschoolers (4-5years), school-age children $(6-11$ years), adolescents (12-16 years). Outcome of treatment was measured as: discharged without deformity, discharged with deformity, discharged against medical advice or death. Statistical analysis was carried out using the software IBM Statistical Package for the Social Sciences (SPSS) for Windows, Version 21.0. (Armonk, NY: IBM Corp.) Descriptive statistics were used to display single variable quantities using means and standard deviations for continuous variables or proportions for categorical variables. The correlation between development of complications and prior treatment by TBS was determined using chi-squared tests. The degree of significance of statistical difference was attributed to a $p$-value $<0.05$.

\section{Results}

During the five-year study period, 52 children with 54 long bone fractures were seen. Their ages ranged from 1 day to 16 years with a mean of $8.85 \pm 3.86$ years. There were 29 males $(55.8 \%)$ and 23 females (44.2\%). School-age children were the most affected group of $(\mathrm{n}=25,48.1 \%)$. This was followed by adolescents $(\mathrm{n}=14,26.9 \%)$ and preschoolers $(\mathrm{n}=10,19.2 \%)$ as shown in Figure 1. The aetiology of childhood fractures included RTC $(\mathrm{n}=30,57.7 \%)$, falls $(\mathrm{n}=10$, $19.3 \%)$, sports injuries $(n=8,15.4)$. Among the road traffic-related victims, majority $(n=24,80.0 \%)$ were unguarded children hit by vehicles while crossing streets. (Table 1)

The tibia was the most commonly fractured long bone in the study $(n=19,35.2 \%)$. This was followed by the femur $(n=14,25.9 \%)$, distal radius $(n=14,25.9 \%)$ and supracondylar part of the humerus $(\mathrm{n}=7,13.0 \%)$. (Figure 2) Most of the fractures $(n=37,68.5 \%)$ were close while the rest were open $17(31.5 \%)$. Majority of the open fractures were tibial fractures $(52.9 \%)$. Forty two patients $(80.8 \%)$ presented directly to the hospital following injury while 10 (19.2\%) did following prior treatment by traditional bone setters (TBS). There was a statistically significant correlation between prior TBS treatment and development of complications hospital $(\mathrm{p}<0.001)$. Limb gangrene $(\mathrm{n}=4,33.3 \%)$ was the most common complication recorded. Others were compartment syndrome $(n=2,16.7 \%)$ and superficial wound infection $(n=3,25.0)$. (Table 2)

Treatment modalities employed in treating children with fractures in this study included casting $(n=26$, $53.1 \%)$, preliminary traction followed by casting $(\mathrm{n}=6$, $12.2 \%)$ and open reduction internal fixation $(n=7$, $14.5 \%$ ) as shown in Table 3. Majority of patients $(\mathrm{n}=40,76.9 \%)$ were discharged without disability, 4 $(7.7 \%)$ were discharged with disabilities and 7 (13.5\%) took their leave from the hospital against medical advice. A patient with associated severe head injury died $(1.9 \%) 5$ days after admission. 


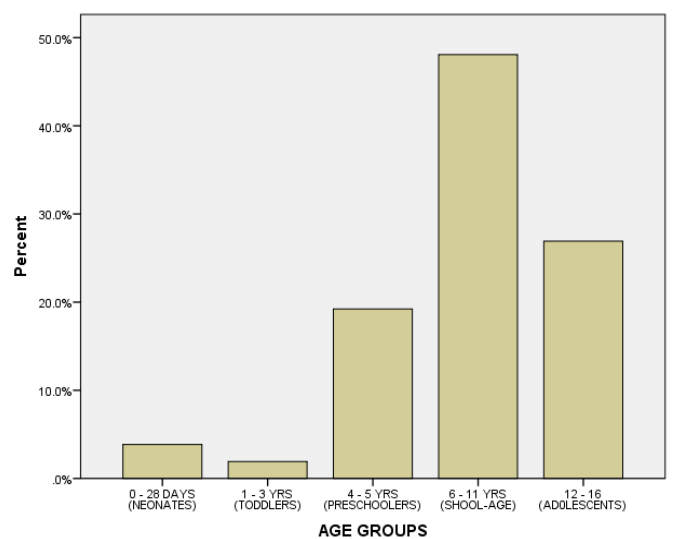

Fig. 1 The distribution of patients according to age groups

Table 1: The aetiology of paediatric fractures

\begin{tabular}{lll}
\hline Aetiology & & Frequency (\%) \\
\hline Road traffic crash & Pedestrians & $24(80.0)$ \\
& Passengers & $5(16.7)$ \\
& Motorcycle rider & $1(3.3)$ \\
Falls & Fall from great height & $7(13.5)$ \\
& Same-level fall & $3(5.8)$ \\
Sports & & $8(15.4)$ \\
Gunshots & & $2(3.8)$ \\
Birth injuries & & $2(3.8)$ \\
Total & & $\mathbf{5 2}(\mathbf{1 0 0 . 0})$ \\
\hline
\end{tabular}

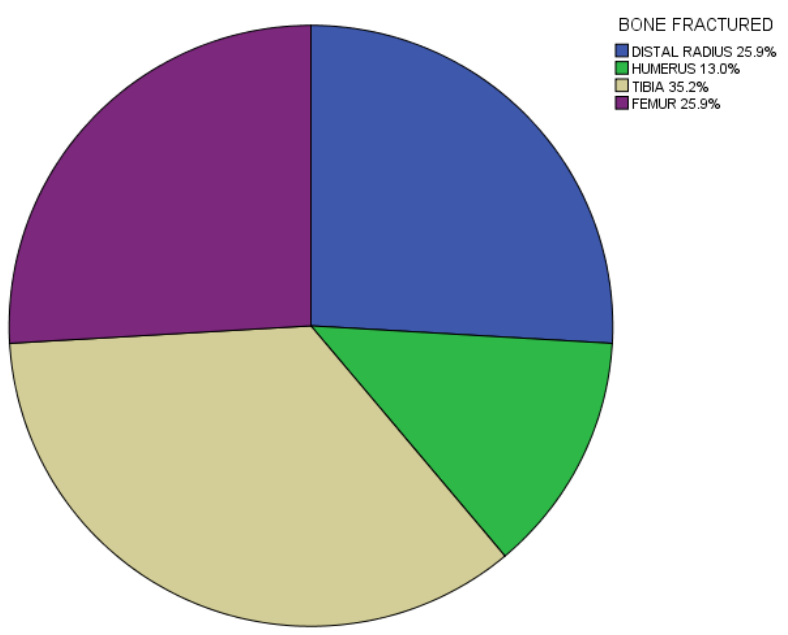

Fig. 2: Pie chart showing the long bones fractured
Table 2: Definitive treatment modalities offered to patients

\begin{tabular}{ll}
\hline Definitive treatment & Frequency (\%) \\
\hline Casting & $26(54.2)$ \\
Open reduction and internal fixation & $7(14.6)$ \\
Traction & $6(12.5)$ \\
Fasciotomy & $3(6.3)$ \\
Amputation & $3(6.3)$ \\
External fixation & $2(4.2)$ \\
Disarticulation & $1(2.1)$ \\
Total & $\mathbf{4 8 ( 1 0 0 . 0 )}$ \\
\hline
\end{tabular}

\section{Discussion}

School-age children were the most common age group that sustained fractures in this study. This finding corresponds to those of similar studies in Nigeria. ${ }^{9,16}$ Children become very adventurous about this age placing them at risk of injuries in schools and homes. A good number of unaccompanied pupils commute to school with the attendant risk of traffic injuries. Of particular note in Nigeria is the menace of street hawking among children in a bid to financially support their families; this inadvertently exposes them to, among other things, trauma. ${ }^{9}$ Poverty is central to most factors that have encouraged a dramatic increase in child street hawking. ${ }^{17}$ A worldwide innovation that has helped to take children off the streets is the School Feeding Programme (SFP). ${ }^{18}$ Children are fed meals in schools and this helps get them into schools and keep them there, through enhancing enrollment and reducing absenteeism. ${ }^{19}$ Apart from keeping children in school and providing nutrition, the programme promotes local agriculture by using locally-sourced food, providing regular orders and a reliable income for local farmers thereby alleviating poverty. ${ }^{17} \mathrm{~A}$ comprehensive SFP in Nigeria could reduce the number of children on the streets, alleviate poverty among their parents and possibly reduce childhood traffic injuries.

In this study, RTC were the major causes of fractures which are in agreement with studies done in other African settings. ${ }^{8,9,13}$ However, studies carried out in high-income countries of England and Oman have reported falls as the major cause of childhood fractures. ${ }^{14,15}$ Africa has the highest per capita rate of road fatalities in the world and road deaths in SubSaharan Africa are projected to more than double from 2015 to $2030{ }^{23}$ Road users in Nigeria are particularly prone to traffic injuries because of the poor state of the roads, lack of enforcing traffic regulations, lack of a school bus transport system and paucity of pedestrian walkways and crossings. Walkways are important in transportation as they 
provide a safe path for pedestrians separate from motorized traffic. They aid road safety by minimizing interaction between pedestrians and motorized traffic. Over $80 \%$ of children who sustained fractures in this study were pedestrians knocked down by motorcycles or automobiles. Modification of busy roads commonly used by school children by placing and enforcing speed limits, installing speed breaks and increasing the number of pedestrian ('zebra') crossings have been found to significantly reduce RTA among children. ${ }^{24}$ This could be adopted in the study area.

Fractures following falls were the second most prevalent mechanism of injury for childhood fractures in this study. Falls from great heights constituted the majority of cases. They were mostly from falls from mango trees. Children fall off the tender branches of these trees while climbing to play or obtain fresh fruits.

The tibia was the most frequently fractured long bone in this study. This finding is in contradistinction to most studies which report the forearm bones as the most commonly fractured in children. ${ }^{16,22,25}$ It is thought that most children fracture their upper limb bones as they attempt to break falls with outstretched arms. The tibia, followed by the femur, was most affected in this study probably because RTC were the most common mechanism of injury in this study. The tibia is subcutaneous mostly in its anteromedial border which predisposes it to open fractures in bumper injuries. ${ }^{26}$ The tibia is also very prone to injuries in motorcycle crashes which are common in Makurdi. ${ }^{27}$ These may explain the preponderance of tibial fractures in the study.

Males formed the majority of the children in this study which is similar to other studies ${ }^{9,28,29}$ This finding may be due to the fact that male children are more adventurous and playful subsequently more prone to injuries than girls. About a third of the patients $(31.4 \%)$ sustained open fractures. This figure is similar to that of a series done in Nigeria. ${ }^{9}$ However some studies have reported very low figures for open fractures in children. ${ }^{22,}{ }^{30}$ The relatively high rate of open fractures in this study may be because RTC were the predominant mechanism of injury and are probably likely to result in high energy transfer. The most commonly fractured bone was the tibia which is also prone to fractures that are open in nature because of the poor soft tissue cover in its anteromedial aspect. Head injuries were the most common associated injuries.
Non-operative fracture treatment (casting with or without prior traction) was the most common modality documented in this study (64.6\%). This is similar to findings obtained in other studies on childhood fractures. $9,12,16$ Non-operative management is the mainstay of treatment of paediatric fractures, with reported good outcomes owing to the very thick and active remodeling potential of children's periosteum along with large haematoma formation which speed up the fractures healing process. ${ }^{12}$ Operative treatment was employed in a minority of patients $(n=9,18.8 \%)$ mainly in those with displaced fractures that could not be satisfactorily reduced close or those that were open. Five patients had limb ablation surgeries (4 had major amputations, 1 disarticulation). These were patients who first presented to TBS and had tight encircling splints applied to the limbs. The menace of TBS in fracture management in Nigeria has been welldocumented. $^{31,32}$ Despite their drawbacks, they continue to enjoy good patronage among fracture patients. Various measures have been suggested to help make their practice safer. These include incorporating them into the Primary Health Care system followed by training and re-training in safe handling of fractured limbs. ${ }^{31}$ It is particularly disheartening when children end up with preventable permanent disabilities they will have to carry for the rest of their lives.

Complications were recorded in $21.5 \%$ of fractures studied. The most serious complication was gangrene following tight limb splinting from TBS. Prior consultation of a TBS was strongly correlated with occurrence of complications $(\mathrm{p}<0.001)$.

\section{Conclusion and Recommendations}

Paediatric fractures in BSUTH were more common in males and caused mostly by RTC. Non-operative treatment modalities were the most commonly employed. There were few complications with most patients discharged without deformities. Public enlightenment on trauma prevention and enforcement of school bus transport system may help reduce incidence of paediatric fractures. 


\section{References}

1. Oboirien M. Pattern of paediatric trauma in Sokoto, North West Nigeria. Afr J Paediatr Surg 2013;10:172-5

2. Simon R, Gilyoma JM, Dass RM, Mchembe MD, Chalya PL. Paediatric injuries at Bugando Medical Centre in Northwestern Tanzania: A prospective review of 150 cases. $J$ Trauma Manage Outcomes. 2013;7:10. doi: 10.1186/17522897-7-10.

3. Holder Y, Peden M, Krug E, Lund J, Gururaj G, Kobusingye O. Injury Surveillance Guidelines. Geneva: World Health Organization; 2001. Available from: http://www.who.int/violence_injury_prevention/media/en/13 6.pdf. (Accessed on 29 April 2018)

4. Landin L. Epidemiology of children's fractures. J Pediatr Orthop B 1997;6:79-83.

5. Alison M. Boyce, Rachel I. Gafni; Approach to the Child with Fractures, The Journal of Clinical Endocrinology \& Metabolism. 2011; 96 (7): 1943-52. https://doi.org/10.1210/jc.2010-2546

6. Worlock P, Stower M. Fracture patterns in Nottingham children. J Pediatr Orthop. 1986; 6(6):656-60.

7. Rennie L, Court-Brown CM, Mok JYQ, Beattie TFl. The epidemiology of fractures in children Injury. 38(8):913 - 922

8. Archibong AE, Onuba O. Fractures in children in south eastern Nigeria. Cent Afr J Med. 1996;42(12):340-3.

9. Nwadinigwe $\mathrm{CU}$, Ihezie $\mathrm{CO}$, Iyidiobi EC. Fractures in children Nigerian Journal of Medicine 2006 15(1): 81-86

10. WHO World report on child injury prevention Children and road traffic injury (accessed on $31^{\text {st }}$ May 2018) at: http://www.who.int/violence_injury_prevention/child/en/

11. Sangowawa AO, Adebiyi AO, Faseru B, Popoola OJ. An observational study of road safety around selected primary schools in Ibadan municipality, Oyo State, Southwestern Nigeria. Ann Afr Med 2012;11:32-5

12. Guifo ML, Tochie JN, Oumarou BN et al. Paediatric fractures in a sub-saharan tertiary care center: a cohort analysis of demographic characteristics, clinical presentation, therapeutic patterns and outcomes. The Pan African Medical Journal. 2017;27:46. doi:10.11604/pamj.2017.27.46.11485

13. Lindaman LM Bone healing in children .Clin Podiatr Med Surg. 2001;18(1):97-108.

14. Onyemaechi NOC, Lasebikan OA, Elachi IC, Popoola SO, Oluwadiya KS. Patronage of traditional bonesetters in Makurdi, north-central Nigeria. Patient Preference and Adherence 2015; 9: 275-279.

15. Hyder A, Sugerman D, Puvanachandra P, et al. Global childhood unintentional injury surveillance in four cities in developing countries: a pilot study. Bull World Health Organ. 2009;87:345-52.

16. Adewole OA, Kayode MO, Shoga MO, Williams OM, Ikem IC. Pattern and Trauma Mechanisms of Paediatric Long Bone Fractures in Lagos, Nigeria. Nigerian Journal of Orthopaedics and Trauma 2011; 10(11): 100 - 104

17. Charles OC, Charles AO. Family of child labour: A study of child hawkers in Calabar. Journal of Social Development in Africa $2004 ; 4: 12-21$
18. Taylor AD, Christiana, Ogbogu CO The Effects of School Feeding Programme on Enrolment and Performance of Public Elementary School Pupils in Osun State, Nigeria World Journal of Education 2016; 6(3): 39-47

19. The World Bank Improving Africa's School Feeding Programs: Analysis Sheds Light on Strengths, Challenges http://www.worldbank.org/en/news/feature/2016/06/09/impro ving-africas-school-feeding-programs-analysis-sheds-lighton-strengths-challenges (accessed on 1 May 2018)

20. Nwomeh BC, Ameh EA. Paediatric trauma in Africa. African Journal of trauma 2003; 1: 7-13

21. Cox PJ, Clarke NM. Improving the outcome of paediatric orthopaedic trauma: an audit of inpatient management in Southampton. Ann R Coll Surg Engl. 1997 Nov; 79(6):441-6.

22. Dinesh D, Varghese TP. Audit of Inpatient Management and Outcome of Limb Fractures in Children Oman Med J. 2011 Mar; 26(2): 131-135.

23. Small M Runji J Managing Road Safety in Africa A Framework for National Lead Agencies SSATP https://www.ssatp.org/sites/ssatp/files/publications/SSATPW P101-Road-Safety-Framework.pdf (accessed on 1 May 2018)

24. Elachi IC, Adekwu A, Audu O, Yongu WT, Bitto TT, Onyemaechi NOC. The profile of trauma-related mortality in Benue State University Teaching Hospital, Makurdi, Nigeria Highland Med Res J 2016;16(2):66-69

25. Cooper C, Dennison EM, Leufkens HGM, Bishop N, van Staa TP. Epidemiology of Childhood Fractures in Britain: A Study Using the General Practice Research Database $J$ Bone Miner Res. 200;19(12):1976-81.

26. Chua W, Murphy D, Siow W, Kagda F, Thambiah J. Epidemiological analysis of outcomes in 323 open tibial diaphyseal fractures: a nine-year experience. Singapore Med J. 2012;53(6):385-9.

27. Elachi IC, Okunola BB, Yongu WT, Onyemaechi NO, Odatuwa-Omagbemi OD, Ahachi $\mathrm{CN}$, et al. Motorcyclerelated injuries at a university teaching hospital in north central Nigeria. Niger Med J 2014;55: 452-5.

28. Deakin DE, Crosby JM, Moran CG, Chell J Childhood fractures requiring inpatient management. Injury. 2007; 38(11):1241-6.

29. Hedström EM, Svensson O, Bergström U, Michno P. Epidemiology of fractures in children and adolescents: Increased incidence over the past decade: a population-based study from northern Sweden. Acta Orthopaedica. 2010; 81(1):148-153. doi:10.3109/17453671003628780.

30. Jones BG, Duncan RDD. Open tibial fractures in children under 13 years of age: 10 years' experience. Injury 2003; 34: $776-780$.

31. Elachi IC, Songden ZD, Yongu WT, Kortor JN, Mue DD. Causal conditions for major limb amputation at a specialist hospital in North Central Nigeria. Jos Journal of Medicine 2013;7(2): 41-5.

32. Onyemaechi NOC, Lasebikan OA, Elachi IC, Popoola SO, Oluwadiya KS. Patronage of traditional bonesetters in Makurdi, north-central Nigeria. Patient Preference and Adherence 2015; 9: 275-279. 